\title{
A Review on Beneficiaries' Contentment Towards Medical Services Under Employees' State Insurance Scheme
}

\author{
Sapna Bansal ${ }^{1}$, Tripta Goel ${ }^{2 *}$ \\ ${ }^{1}$ Assistant Professor, Faculty of Commerce \& Management, BMU, Rohtak, INDIA \\ ${ }^{2}$ Research Scholar, Faculty of Commerce \& Management, BMU, Rohtak, INDIA \\ *Corresponding author: triptagoel007@ gmail.com
}

\begin{abstract}
WCI (Workers' Compensation Insurance) is a large-scale social security programme. In contrast to health insurance, this type of insurance covers all medical expenses, regardless of how much the covered individual provides. The study's key objectives are to increase policy understanding and satisfaction with the Employee State Insurance Corporation (ESIC). The benefits of Employees' State Insurance (ESIS) were investigated as part of the study.
\end{abstract}

KEYWORDS: ESIS, employee satisfaction, social security, benefits.

\section{INTRODUCTION}

The health industry in every country is today very competitive as a result of the current time of globalization. The Indian health sector is becoming more competitive on a global scale by improving services and consumer satisfaction. The quality of health-care services they receive is becoming increasingly important in determining beneficiary satisfaction. The Employees' State Insurance Scheme is a social safety net that protects employees as well as their family members who work in covered businesses. Social security is important in society because it helps to reduce financial and social status inequities. It accomplishes this by ensuring a safe and secure working environment. Social Security removes all types of prejudice by making benefits available to everyone, regardless of nationality, ethnicity, or gender. Under the Employees' State Insurance Act, employers, employees, and the state all contribute to a fund that provides various benefits to recipients. Under the Act, this employee's benefits are calculated based on his or her average daily salary. The Employees' State Insurance Corporation is in charge of it, and the state governments run it. The ESIS was established in 1948 to ensure the financial security of workers in Indian businesses and enterprises. The ESI Scheme was created to reduce the cost of health care. It enables people to receive care that they would not otherwise be able to afford. The ESI Scheme protects families from the financial consequences of illness. It's a system for dispersing the threat. The ESI Act of 1948, India's first social insurance legislation, covers sickness, maternity, temporary or permanent disability, occupational disease, or death due to an industrial injury resulting in a loss of wages or earning capacity-total or partial. As a result, the Act is intended to balance or mitigate physical or financial distress in such situations, preserving human dignity during times of crisis by preventing deprivation, destitution, and social degradation while allowing society to retain and continue socially useful and productive manpower.

The ESI Act applies to non-power-using, non-seasonal factories with ten or more employees, as well as firms with twenty or more employees that are neither powerusing nor non-seasonal. Workers earning up to Rs. 25000 per month are automatically covered by health insurance. Employers must contribute 3.75 percent of the salaries for which their employees are eligible to make premium contributions as part of the plan, while employees must pay 0.75 percent of their wages. Employees earning less than Rs.50 per day are not obligated to contribute to the premiums they must pay. The ESI Fund, which is funded by both employees and employers, is used to cover administrative costs as well as give monetary and medical benefits to IPs and their 
families. The state governments cover the costs of ESIC's medical care, contributing 12.5 percent of the total expenditure (up to Rs.1000 per year per capita) incurred by the ESIC.

\section{VARIOUS BENEFITS UNDER ESI SCHEME}

ESIC provides medical and cash benefits to those who are covered by the programme as part of the Employees' State Insurance Scheme.

\subsection{Sickness Benefit}

Sickness Benefit is a one-time payment paid to an insured person in the event of a medically-verified illness that prevents them from working. Individuals who have completed nine months of insurable employment and have paid or are set to pay payments for at least 78 days in the six-month equivalent contribution period are eligible for the benefit. During two consecutive benefit periods of sickness benefit, a maximum of 91 days of sickness benefit at $70 \%$ of the average daily income is paid out.

An Extensive Sickness Benefit is paid to an insured person who is diagnosed with one of 34 long-term diseases or a rare sickness that requires extended treatment and time away from work. To be eligible for this benefit, the insured must have worked for at least two years in an insurable employment before applying. In the prior four contribution periods, or around two years, there should have been at least 156 days of contribution. If the approved authority provides appropriate medical certification and confirmation of the claim, ESB can be paid for a maximum of two years (including 91 days as SB). This benefit pays out cash equivalent to $80 \%$ of the average daily earnings. After the Branch Office receives all of the claim papers, the award is paid out within seven days.

\subsection{Maternity Benefit}

During a benefit period for Maternity Benefit, benefits are paid to insured women in the case of pregnancy, miscarriage, or illness related to pregnancy. A benefit term is sufficient in cases of new registered Insured Women confinement/miscarriage and illness associated therewith, and a contribution period of at least 70 days must be paid in the two consecutive contribution periods immediately preceding the claim. Benefits are paid for 12 weeks in the case of a normal birth and 6 weeks in the case of a miscarriage, with the possibility of an additional four weeks on medical grounds if the mother's condition improves. The monthly benefit is calculated based on the average daily earnings for the month. The benefit can be claimed once the claim papers have been received and authenticated.

\subsection{Disablement Benefit}

Employees who become handicapped as a result of a work-related injury or disease are covered by their employer's insurance policy and are eligible to disability compensation. To be covered by their policy, an insured individual must be working at the time of the event. For as long as a person is temporarily incapacitated, benefits of $90 \%$ of the average daily wage are paid. If you are permanently incapacitated, you will receive a cash benefit for the rest of your life. The amount of compensation is determined by a Medical Board based on the patient's loss of earning capacity. Disability Benefits will be paid one month after the accident report and claim paperwork are received.

\subsection{Dependents' Benefit}

The dependents' benefit is paid to the surviving family members when an insured individual dies as a result of a job injury or occupational illness. A widow can get this benefit on a monthly basis for the remainder of her life or until she marries again. Unmarried sons and daughters under the age of 25 are eligible for benefits. If specific criteria are met, other dependents, such as parents, such as a widowed mother, may be eligible for this benefit as well.There is a predetermined percentage of dependents who receive $90 \%$ of the average daily earnings. Three months after the insured person's death, the first payment is due, and following payments are made on a monthly basis.

\subsection{Other Benefits}

Some other benefits offered by the Scheme are as follows:

Funeral expenses of up to Rs.10000/- can be paid at the branch office following the death of an I.P. A claim for such compensation must be filed within three months of IP's death.

Vocational Rehabilitation in cases of physical disability caused by a work-related injury that is $40 \%$ or more debilitating to people under the age of 45 . Vocational training can be paid for as long as the course lasts - either the full price charged or Rs.123/- per day, whichever is higher.

Free supply of physical aids and appliances such as crutches, wheelchairs, dentures, spectacles and other such physical aids.

This category also includes services like immunisation and HIV/AIDS testing and treatment.

A confinement allowance of Rs.2500/- is granted when an insured woman or an insured person in respect of his wife is forced to give birth in a location where medical services under the ESI Scheme are unavailable. This cost only includes two confinements.

The Rajiv Gandhi Shramik KalyanYojanagives unemployment benefits to workers who have lost their jobs due to plant closures, retrenchment, or permanent disability caused by a non-work-related injury. Workers who have contributed to their pensions for a minimum 
of three years before their job was ended are eligible for this payment. Unemployment Allowance pays out half of the average daily earnings. This benefit can be received for up to a total of 12 months during the course of your life, either in one lump sum or in multiple payments of no less than one month each. Unemployment Allowance claimants who want to upgrade their abilities can take advantage of AVTI's shorter-term training. The corporation is responsible for the entire expense, including rail transportation to and from the venue.

\section{Review of Literature}

The literature review summarises the findings and conclusions of previous studies on the subject matter as part of a research project. This study draws on previous research on recipients' satisfaction with their state-run insurance company. -

Prakash and Ragavi (2020) utilised SPSS software to investigate how well employees in Coimbatore were aware of and used ESIS benefits. The vast majority of employees, according to this report, are aware of the benefits of ESI services and use them on a regular basis. The raw data was subjected to a number of statistical tests, including the basic percentage, the weighted average, and ranking. Furthermore, data from other sources was included in the final result. The survey found that ESI dispensaries and hospitals were not serving the demands of those who were covered. As a result, the research suggests that providing outstanding services can lead to a highly respected and trusted company.

Jain and Kaondal (2019) looked at how happy ESIC beneficiaries were with five key areas of the organization's services in their SERVQUAL study (responsiveness, tangibility, assurance, reliability, and empathy). According to the study, happiness is linked to tangibility, certainty, and empathy. According to Pearson's coefficient of determination, certainty, tangibility, and empathy are all highly linked.

Masih and Aamir (2018) discovered that ESIS is a good place to start if you want to increase worker health and productivity at work. Despite the fact that the benefits of ESIS should have been obvious, only a small percentage of employees took use of them. Because of the low quality of medical care at Allahabad's ESI Dispensary, employees choose to travel to a private hospital.

According to a study undertaken by Pujari, the Employees State Insurance Scheme in India benefits employers and their families (2018). They benefited from a state-sponsored employee insurance programme. This plan also covers the dependents of employees. Some government employees now get better benefits than those in the private sector as a result of their initiatives. However, there is still work to be done in this area. According to Garg's (2018) research, only workers in the organised sector who are protected by the social security system are entitled for health benefits under the ESI. It covers all medical bills, regardless of how much the policyholder contributes to the overall cost, unlike other types of health insurance. This programme has grown and evolved over the last six decades to create an infrastructure and geographic reach that is unrivalled. Despite this, people who have insurance are dissatisfied.

According to Naveen (2018), the ESIC offered social security to RINL personnel (Rashtriyalspat Nigam Limited). This legislation benefits workers and their families. The ESIC processes used by RINL, on the other hand, may not always meet the insured's expectations. According to the author's findings, ESIC should improve the quality of its pharmaceuticals and the way it treats its staff, as well as ensuring that everyone has access to the most up-to-date information. The company's additional incentives were well-received by its employees.

According to Kumar and Porkalai, employees in the epublishing industry are unaware of ESIC benefits (2017). The company's ESIC plan should be centred on its employees. As a result of this involvement, the level of output will be affected. A company must demonstrate both individual and group improvement in order to be termed "healthy."

According to Pradhan and Kar (2015)'s research, parental benefits for women employees from various sectors are significantly missing. Manufacturing expansion is exceeding insurance coverage expansion, and the gap appears to be widening. India's Maternal Benefit Programs may be tainted if this remains unchecked.

Nayana's research this year focused on a variety of social security programmes. The purpose of social security programmes, according to the conclusions of this study, is to give financial help to individuals in the case of their death, illness, or incapacity. As a result of the ESI system, employees are safeguarded and their productivity is boosted. As a result, the ESI Scheme had a big impact in India. As a result, living and working circumstances in the welfare state have improved. The author claims that investing in the ESI Scheme today will pay off in the near future.

The ESI strategy, according to Umesh, is extremely significant (2016). According to the research, ESI provides a wide range of benefits to its recipients. There aren't many employee benefit plans that are as generous as this one. As a result, individual benefits cannot be delivered on time to the recipients.

Muthulakshmi (2014) examined the efficacy of the Employees State Insurance Scheme using data from the Tuticorin district of Tamil Nadu as a case study. The Employee State Insurance Corporation and ESI employees' impressions of ESI hospitals are investigated in this study. The poll judged ESI dispensaries and hospitals to be disappointing. More research is needed 
to determine how to improve the scheme's dependability and, as a result, provide better services to customers.

According to Lakshmi (2014), the Employees State Insurance Scheme in the Tamilnadu district of Tuticorin performed remarkably well. The study looks at ESI Corporation's operational effectiveness as well as the opinions of ESI employees. Simple percentage analysis, averages, F-statistic, Chi-square test, Garrett ranking, and percentage analysis were among the statistical approaches utilised to investigate the primary data. The survey found that ESI dispensaries and hospitals were not serving the demands of those who were covered. As a result, the research suggests that providing outstanding services can lead to a highly respected and trusted company.

Dash U and Muraleedharan (2011) investigated ESIS utilisation and beneficiaries over time. This research study examines ESI facilities and the extent to which the ESI programme saves beneficiaries money. Overall utilisation is low, according to the survey's findings, due to a lack of employer interest and knowledge about ESI procedures, as well as a perception of low-quality pharmaceuticals, long waiting periods, staff insolence, and long waiting periods for exceptionally long delays in reimbursement of money spent on outside treatment. These variables, according to the study, contribute to a low overall use rate.

Jose conducted an investigation of Kerala's Employees State Insurance Corporation (ESIK) (2006). The corporation had created a broad network of service shops in order to provide a wide range of benefits to insured and their family members, according to the investigation. As a result of these actions, worker productivity will increase, lessening the likelihood of labour disputes. It has aided in the reduction of financial stress in a wide range of situations, as well as the preservation of human dignity in the face of misfortune. According to researchers, the program's service and administration were found to be poor.

\section{CONCLUSION}

Employees and the company must grow together for an organisation to prosper. Workers should be informed on their rights as part of the Employees' State Insurance (ESI) policy, which provides medical and financial security. Benefit programmes should be the company's principal priority. According to the results of this survey, the majority of employees are unaware of the ESI policy. As a result, increasing both policy knowledge and implementation is critical in order to achieve a high level of productivity and a healthy organisation.

\section{REFERENCES}

Annual Reports of Employees State Insurance Corporation.

Arora, A., Chakraborty, P., Bhatia, M. P. S., \& Mittal, P. (2021). Role of Emotion in Excessive Use of Twitter During
COVID-19 Imposed Lockdown in India. Journal of Technology in Behavioral Science, 6(2), 370-377. https://doi.org/10.1007/s41347-020-00174-3

Bhatia, A., \& Mittal, P. (2019). Big Data Driven Healthcare Supply Chain: Understanding Potentials and Capabilities. SSRN Electronic Journal. https://doi.org/10.2139/ssrn.3464217

Chakraborty, P., Mittal, P., \& Arora, U. (2018). Children aged 624 months like to watch YouTube videos but could not learn anything from them. Acta Paediatrica, International Journal of Paediatrics, 107(8), 1461-1466. https://doi.org/10.1111/apa.14291

Chakraborty, P., Mittal, P., Gupta, M. S., Yadav, S., \& Arora, A. (2021). Opinion of students on online education during the COVID-19 pandemic. Human Behavior and Emerging Technologies, 3(3), 357-365. https://doi.org/10.1002/hbe2.240

Giri V.V., Labour problems in Indian Industries 1980, P. 42

Jagannadham, K. S. (1965) Employees' State Insurance Scheme A Critique of the Utilization of Reserve; The Economic Weekly, pp. 786-790.

KudchedKar, L.S. (2010) Aspects of Personal Management and Industrial Relation, 2010, P. 112.

MaiyaUmesh, (2016) "Nurses' Perception towards ESI Scheme: A Study with Reference to Select Hospitals in Udupi District".

Mittal, P. (2020). A multi-criterion decision analysis based on PCA for analyzing the digital technology skills in the effectiveness of government services. In 2020 International Conference on Decision Aid Sciences and Application, DASA $2020 \quad$ (pp. 490-494). IEEE. https://doi.org/10.1109/DASA51403.2020.9317241

Mittal, P. (2020). Big data and analytics: a data management perspective in public administration. International Journal of Big Data Management, 1(2), 152. https://doi.org/10.1504/ijbdm.2020.112415

Mittal, P., \& Raghuvaran, S. (2021). Entrepreneurship education and employability skills: the mediating role of e-learning courses. Entrepreneurship Education, 4(2), 153-167. https://doi.org/10.1007/s41959-021-00048-6

Muthulakshmi.G (2014) A Study on the Performance of The Employees State Insurance Scheme (ESI) With Special reference to Tuticorin District, Golden research thoughts, 17.

N.D. Kappor (2008) Introduction to commercial and Industrial Law, P. 34.

Nyman, J.A, (1999) The value of health insurance: the access motive. Journal of Health Economics, 18, pp. 141-152.

Sharma, A., \& Jose, A. (2020). Internal Migration: Issues Prevailing in the NCT (National Capital Territory) of Delhi. VEETHIKA-An International Interdisciplinary Research Journal, 6(3), 1-17. https://doi.org/10.48001/veethika.2020.06.03.001

Sharma, A.K., (1997) Factors affecting satisfaction from employee's state insurance corporation services provided at the dispensaries, Health and Population - Perspectives and Issues. 20(1), pp. 38-47.

Tealgu Paul (2009) Employees relation Vol. 25, Issue 5 P. 428 452. 